ORIGINAL ARTICLE

\title{
Investigation of systems to prevent diversion of opiate drugs in general practice in the UK
}

\author{
R Baker, P Moss, D Upton, J Pankhania
}

Qual Saf Health Care 2004;13:21-25. doi: 10.1136/qshc.2002.002485

See end of article for authors' affiliations

\section{Correspondence to:}

Professor R Baker, Clinical Governance Research \& Development Unit, Department of Health Sciences, University of Leicester, Leicester General Hospital, Leicester LE5 4PW, UK; rbl4@le.ac.uk

Accepted 15 August 2003
Background: Statutory regulations govern the procedures that must be followed by general practitioners (GPs) in the UK to minimise the risk of diversion of prescribed opiate drugs for illicit use. However, evidence presented at the trial of Harold Shipman, a GP convicted of murdering patients with diamorphine, suggests that the regulations and monitoring of GPs' prescribing are failing.

Aim: To assess the policies followed by general practices in Leicestershire and Rutland with regard to the controlled drugs regulations.

Methods: A semi-structured interview was administered to a purposeful sample of lead GPs to explore how their practices applied the regulations. The controlled drugs registers and drug storage facilities in these practices were inspected. A questionnaire was sent to all the remaining practices to seek information about their application of the regulations, any concerns they had about the regulations, and any suggestions for improving them.

Results: Of the 142 general practices in Leicestershire, the lead GP in 14 took part in the interviews. Respondents expressed dissatisfaction with current policies including the design of controlled drug registers, and generally supported the reintroduction of an inspection scheme. Ninety $(70.9 \%)$ of the 127 practices to whom the questionnaire was sent responded and, of these, 31 (34.4\%) no longer held a supply of controlled drugs. Those that did hold controlled drugs indicated concern about the regulations, confusion about some aspects including the return and disposal of unused drugs, and a desire for advice and support in the implementation of the regulations. Forty two of the 59 respondents who held a supply of controlled drugs (71.2\%) would welcome regular inspection.

Conclusion: GPs are confused about the controlled drugs regulations and have little support in implementing them. The suspension of inspection schemes has reduced the amount of advice and support available to them and, in consequence, the regulations are interpreted differently in different practices. These findings are cause for concern about the risk of diversion of controlled drugs, and illustrate how patient safety systems can decay when they are not maintained.
$\mathrm{T}$ he handling and administration of drugs that have potential for abuse ("controlled drugs") is regulated in the UK by specific legislation. The principal regulations are the Misuse of Drugs Act 1971 and the Misuse of Drugs Regulations 1985 (updated version issued in 2001). ${ }^{1}$ These regulations define the drugs subject to special controls and lay down the procedure a general practitioner (GP) must follow in writing a prescription for an opiate, the registers that must be kept of the drugs held and administered by the GP, systems for the secure storage of opiates and other controlled drugs, and arrangements for the destruction of unused drugs (box 1). The purpose of the regulations is to protect patient safety by minimising the risk of drug abuse by both health professionals and patients.

In general practice the regulations were backed up by a system of regular inspections by regional medical officers until 1991 when the regional medical officer service was abolished. The Misuse of Drugs Act 1971 empowers the government to authorise other persons to undertake inspections and, from 1991, doctors with local responsibilities for prescribing policies (referred to as medical advisors) were authorised to take on inspection functions for local health authorities. However, following several health service reorganisations in the past decade, few medical advisors now remain in post.

General practitioners who provide emergency care to patients generally include an opiate analgesic in their medical bags. They are recommended to use diamorphine or morphine for patients with acute myocardial infarction and left heart failure, ${ }^{2}$ and may also administer these drugs during the management of terminal illness. Since opiate drugs may be abused by both health professionals and members of the public, the use and storage of opiate drugs is subject to regulation, the aims of which are to prevent drugs intended for patients being misused by others (a phenomenon referred to as diversion $\left.{ }^{3}\right)$. It is well established that the diversion of prescribed drugs by drug users in the UK is a significant problem, ${ }^{4}$ but the extent of diversion of drugs prescribed for therapeutic purposes is less clear. In the US there does not appear to be an association between the increased use of opiates to treat pain and increased opioid abuse. ${ }^{5}$ Furthermore, draconian measures to control the use of opiates can have the adverse consequence of reducing the availability of these drugs during palliative care. ${ }^{6}$

Concern about the security of the current system to prevent diversion of opiates and other controlled drugs from general practice increased in the UK following the conviction of a GP, Harold Shipman, for the murder of 15 of his patients (box 2). Patient safety may be compromised by the deliberate criminal or malicious behaviour of a small number of health professionals, but error and vulnerable systems are the more common dangers to safety. ${ }^{8}$ If the weaknesses of the current system for preventing diversion of controlled drugs revealed by Shipman's activities are widespread, there may be a significant risk of misuse of prescribed opiates. In the light of this concern, a joint district body responsible for local services for the care of drug misusers and policies to reduce misuse (the drug and alcohol action teams of Leicester, Leicestershire 
Box 1 Features of the regulations under the Misuse of Drugs Act 1971 and the Misuse of Drug Regulations 1985

\section{Prescriptions}

- In the prescriber's handwriting, showing patient's name and address, dose to be taken, form (tablets, injections), and total quantity of the drug in both words and figures.

\section{Registers}

- Must be kept for recording transactions of controlled drugs including opiates. The register must be bound (not loose leaf), entries must be in chronological order made on the day on which the drugs were obtained or supplied, no entry may be cancelled or obliterated, must be indelible.

\section{Destruction}

- Can only occur in the presence of an authorised person (a police officer or other specified person). A record must be made of the date and quantity destroyed and signed by the authorised person.

\section{Storage}

- Controlled drugs must be kept in a locked receptacle.

and Rutland) commissioned a study to investigate the risk of diversion of controlled drugs and provide guidance on how the risk could be reduced.

In this paper we report the findings of the study undertaken in general practice. The specific aims of the study were to describe the systems used by GPs and to seek their views on how systems could be improved.

\section{METHODS}

The study took place in the two counties of Leicestershire and Rutland and was approved by Leicestershire research ethics committee. There were 142 general practices in these counties at the time of the study (autumn 2001), and we sought to obtain views from all of them. Two methodological approaches were adopted: interviews of lead GPs from a sample of practices and a questionnaire survey of the remaining practices.

\section{The interviews}

Interviews were undertaken to explore the range of views of GPs in different types of practices, to inform the development of the questionnaire, and to enable inspection of drug registers and storage facilities. A letter was sent to all practices in Leicestershire and Rutland inviting them to nominate one of their GPs to take part in an interview about their systems to prevent diversion of controlled drugs. The letter also indicated that the practice controlled drugs registers and storage facilities would be inspected. We sought to select from those who responded a mix of practices, including single handed and group practices, dispensing and non-dispending practices, and those in inner city, suburban and rural settings.

A semi-structured interview schedule was devised (box 3) and further developed during the course of the interviews. The questions were initially developed following discussion with the drug and alcohol action teams and in the light of the findings of the Shipman investigation. ${ }^{7}$ Closed questions were used to describe the systems used by practices, and open questions to enable respondents to express their concerns about the risks of diversion and ideas about how the risks
Box 2 Summary of the findings of the review of Harold Shipman's clinical practice, 1974-98

\section{Background}

- Convicted in January 2000, Harold Shipman was found to have administered lethal doses of diamorphine to his patients, having obtained the diamorphine by writing prescriptions that he personally collected from a pharmacist or by retaining unused diamorphine left over following care of people with terminal illness.

\section{Deaths}

- In a review undertaken following Shipman's conviction, the excess number of deaths occurring at home or on practice premises and certified by Shipman during his career as a GP was 236 (95\% Cl 198 to 277 ).

- The excess was associated with a higher proportion of deaths occurring in the afternoon, on week days, and with Shipman present than the deaths of patients of a matched sample of local GPs.

\section{Prescribing}

- Shipman did not maintain a controlled drugs register because he claimed he did not have controlled drugs in his possession. He issued (and collected) prescriptions for single doses of $30 \mathrm{mg}$ diamorphine injection, but it could not be confirmed that the named patient had received the drug. He prescribed substantial quantities of diamorphine for patients being cared for at home with terminal illnesses. It was established at his trial that he had collected unused diamorphine from patients' homes.

\section{Recommendations made in the review}

- An effective system for the inspection of GPs' controlled drugs registers should be introduced.

- GPs should record batch numbers in clinical records when they personally administer controlled drugs, and batch numbers should be included in the controlled drugs registers of GPs and pharmacists.

could be reduced. The interviews were administered by a non-clinician (PM) to the nominated GP in each practice. Interviews lasted 30-40 minutes and were recorded and transcribed. Responses to the closed questions were analysed quantitatively. To analyse the open questions, transcripts were repeatedly studied until the issues of concern to the GPs had been identified. Interpretations of interviews were agreed between two researchers (PM and RB).

The controlled drug registers and storage facilities were inspected by a clinician (RB) to determine whether the systems in use were in accordance with the regulations (box 1). In addition, a record was made of the methods of storage and the type of controlled drug registers in use. Since the inspection of drug registers and storage facilities might lead to the discovery of inappropriate practice policies, it was agreed with the local medical committee-the statutory body with responsibility for representing the interests of GPs-that, if significant concerns about the policies in a particular practice were identified, the matter would be reported to the local health authority for action to be taken.

\section{The survey}

The questionnaire was devised in the light of the findings from the initial interviews. Questions were included about 
Box 3 Outline of interview schedule

Practice background

- Description of staff involved in managing patients prescribe controlled drugs, conditions for which controlled drugs were used, perceptions about the volume of controlled drugs prescribed by the practice.

Administration of controlled drugs by doctors

- Who records use of drugs, what details are recorded where, any monitoring procedures in use, level of confidence in systems in use, and suggestions for improvements.

\section{Storage}

- Policies followed, confidence in these policies, and suggestions for improvements.

Unused and returned controlled drugs

- Policies followed, methods of disposal, level of confidence, and suggestions for improvements.

\section{General matters}

- How practices keep up to date with clinical advice about the use of controlled drugs, local sources of advice, and any other comments.

the storage of controlled drugs, the information recorded in controlled drugs registers, the disposal of out of date and unused stock, policies on the handling of drugs returned by patients or carers, and views about the acceptability of an inspection scheme and the need for advice and support for practices about the prescribing and administration of controlled drugs. In addition, open questions were included to ask respondents about their concerns about systems to prevent diversion and to seek suggestions for improvement. The questionnaire is available on the QSHC website at www.qshc.com/supplemental.

The questionnaire was mailed to all practices that had not been involved in the interviews. It was addressed to the practice manager with instructions that it should be completed by one of the doctors in the practice. A reminder was sent to non-responders after 3 weeks. Data from the completed questionnaires were entered into a database and descriptive statistics used to identify the proportions of practices with different controlled drug storage and register systems, their views on the security of current systems, and their ideas on how the systems could be improved.

\section{RESULTS}

\section{Interviews}

Sixteen practices identified themselves as willing to take part in the interviews, but two of these withdrew because of the illness of a doctor in each practice. Interviews were completed with the nominated doctor in the other 14 practices. Six were single handed (one dispensing) and eight were group practices (one dispensing). The numbers of partners in the group practices varied from three to eight, and the mean number of years interviewees had been working as GPs was 16 (range 7-29). Five practices were inner city, seven suburban, and two rural.

Four practices did not keep or store controlled drugs, either because they undertook little or no out of hours work themselves or because they used alternative medication-for example, nalbuphine injection in place of diamorphine. Drugs were stored in three locations: a practice stock in a locked cupboard or dedicated drug storage cabinet; in the doctor's own medical bag; and/or in a practice emergency bag. In two of the 10 practices drugs were kept only in the doctor's medical bag. Inspection confirmed that, in the eight practices that held a supply of controlled drugs on the premises, secure safes or storage cupboards were used. In the dispensing practices, controlled drugs were stored in dedicated cabinets separated from other drugs.

A variety of drug registers were in use. Seven practices used a standard register published by the National Pharmaceutical Association but three used notebooks modified for the purpose. Both standard registers and modified notebooks had been altered by some practices to enable recording of batch numbers and total amount of drug in stock. Doctors who carried drugs in their bags also maintained personal registers, most commonly ruled notebooks. However, the format was inconsistent and one practitioner was so dissatisfied with current arrangements that he had devised a computerised system incorporating a permanent audit trail. Monitoring of practice registers and the stock of controlled drugs was undertaken by practice nurses (or dispensing staff in dispensing practices). Monitoring was undertaken at variable intervals, from daily to annually. No practice could recall having received an external inspection of their registers or storage arrangements for at least 10 years. Several respondents supported the reintroduction of some form of inspection-for example, one GP commented:

"No, I'm not satisfied with the present arrangements. I think they are hopeless. I mean, I think it was better when we had the regional medical officer come to inspect.... You could leave it in his hands to see whether the books and everything in the cupboard tallied. You know, it's quite complicated, I think, to work out."

Only two practices accepted the return of unused controlled drugs to the practice. The other 12 regarded returned drugs as an additional problem best left to pharmacies. Two practices reported that community nurses would collect unused controlled drugs and return them to a pharmacy on behalf of patients or carers. Some doctors were particularly concerned about the arrangements for the disposal of controlled drugs following the death of a patient at home:

"I don't think at the moment there is a requirement that we have a register of controlled drugs that are returned. I think it could be legislated to ensure that these controlled drugs are disposed of properly. I don't think there are any rules or advice or anything that I should tell patients what to do with controlled drugs."

\section{The questionnaire survey}

Fourteen of the 142 practices in Leicestershire and Rutland had provided information about their controlled drug systems through participation in the interviews, and these were therefore excluded from the postal survey. One of the remaining practices had merged with another practice before the survey was undertaken, so a total of 127 practices were included. Ninety $(70.9 \%)$ responded after two mailings. Of these, $20(22.2 \%)$ were single handed (for six respondents, information about whether the practice was single handed or a group was not available). Thirty five $(27.6 \%)$ of the 127 practices included in the survey were single handed. Sixteen $(17.8 \%)$ responding practices were dispensing compared with $18(14.4 \%)$ of the 127 practices included in the survey.

Fifty nine $(65.6 \%)$ respondents reported that they held a supply of controlled drugs, stored most commonly in a practice cabinet or doctor's bag, although all but 19 of these practices stored drugs in more than one place (table 1). All practices used some form of register and 20 practices had more than one register. The standard register published by the National Pharmaceutical Association was used by 23 practices and another 23 used notebooks, the layout of which they had designed themselves. The total quantity of controlled drugs held was recorded in only $16(69.6 \%)$ of 
the standard registers, $18(78.3 \%)$ of the practice notebooks, and $22(66.7 \%)$ of the doctors' notebooks. Practices reported a variety of policies on the destruction of unused controlled drugs. Two practices reported storing outdated drugs indefinitely because the police had refused to collect them for authorised disposal.

Of those practices that held controlled drugs, more than half had not been inspected in the previous 10 years (table 2 ). Eighteen (30.5\%) had undergone some form of inspection in the previous 5 years. Forty two $(71.2 \%)$ respondents would welcome regular external inspection and 33 (55.9\%) would welcome unannounced inspections. Thirteen reported anxieties about stock control and storage, including the regular maintenance of registers and concern about delay in the destruction of unused drugs.

Of the 90 respondents, 69 (76.7\%) did not usually permit unused drugs to be returned to the practice by patients or carers, and only eight encouraged this policy. Those practices that did accept unused drugs either returned the drugs to a pharmacy for destruction, destroyed them within the practice, or handed them to the police for destruction. One practice reported that unopened drugs would be added to the practice stock.

Most practices reported that they would find a source of support and advice useful. Generally they preferred local health service organisations such as the local drug and alcohol action team, health authority or primary care trust to take on this role (table 3 ).

\section{DISCUSSION}

The findings of this study indicate a number of weaknesses in the systems currently in use. These include use of controlled drugs registers that do not comply with the regulations, confusion among GPs about the details of the regulations, anxiety about the systems in use, and dissatisfaction with the availability of advice and support. The controlled drugs regulations have been in force for many years, but arrangements to ensure they are still followed appear to have lapsed and the systems operated by practices have consequently degraded. The regulations may be regarded as a system that has fallen into some neglect, consequently increasing potential risks to patients.

Some qualifications about the study should be noted. It was undertaken in one health district only and cannot be

Table 1 Methods of storing controlled drugs, registers in use, and policies on disposal of outdated stock ( $n=59$ practices)

\begin{tabular}{|c|c|c|}
\hline & $\mathbf{N}$ & $\%$ \\
\hline \multicolumn{3}{|l|}{ Storage of controlled drugs: } \\
\hline In doctor's bag & 36 & 61.0 \\
\hline Locked cabinet or safe & 46 & 78.0 \\
\hline Emergency practice bag & 9 & 15.3 \\
\hline Locked case & 1 & 1.7 \\
\hline \multicolumn{3}{|l|}{ Registers: } \\
\hline Standard register only & 11 & 18.6 \\
\hline Practice notebook only & 15 & 25.4 \\
\hline Doctor's notebook only & 13 & 22.0 \\
\hline Standard register plus doctor's notebook & 12 & 20.3 \\
\hline Practice notebook plus doctor's notebook & 8 & 13.6 \\
\hline \multicolumn{3}{|l|}{ Disposal of outdated stock: } \\
\hline Destroyed at the practice by an individual & 5 & 8.5 \\
\hline $\begin{array}{l}\text { Destroyed at the practice before another } \\
\text { member of staff }\end{array}$ & 11 & 18.6 \\
\hline $\begin{array}{l}\text { Destroyed at the practice before an } \\
\text { authorised witness }\end{array}$ & 15 & 25.4 \\
\hline Returned to a pharmacy & 20 & 33.9 \\
\hline Destroyed by police & 6 & 10.2 \\
\hline Other & 2 & 3.4 \\
\hline
\end{tabular}

Table 2 Time since last inspection of controlled drug registers and views on regular external scrutiny of registers ( $n=59$ practices)

\begin{tabular}{lrr} 
& N & $\%$ \\
\hline Last external inspection of register: & & \\
Within last 12 months & 6 & 10.2 \\
1-5 years ago & 12 & 20.3 \\
5-10 years ago & 9 & 15.3 \\
>10 years ago & 31 & 52.5 \\
Would welcome independent scrutiny: & 5 & \\
Very much & 37 & 8.5 \\
Yes & 14 & 62.7 \\
Rather not & 3 & 23.7 \\
Absolutely not & 5.1 \\
Would welcome unannounced independent & & \\
scrutiny: & & \\
Very much & 2 & 3.4 \\
Yes & 31 & 52.5 \\
Rather not & 20 & 33.9 \\
Absolutely not & 5 & 8.5 \\
\hline *One non-response. & & \\
\hline
\end{tabular}

assumed to be representative of all practices in England. For example, some districts may have implemented local advice and support schemes, although we believe such schemes are uncommon. Our findings are likely to be typical of those districts such as that in which Shipman worked that did not have local arrangements to ensure the provision of advice backed up by regular inspections. Other than the small number of practices that were inspected in our study, the findings are based on self-reports and respondents may have sought to indicate that their practice policies were in accordance with the regulations. Furthermore, the practices that did take part are likely to have been those which were more confident about their own policies, and the policies followed by non-responders may have been even less in accordance with the regulations.

The findings indicate that practices are uncertain about the policies they should follow to prevent diversion of controlled drugs, and that some are anxious about this state of affairs. Practices are attempting to apply sensible policies but are unsure what the policies should be; consequently, different practices are applying different policies and, in some cases, regulations have not been followed. For example, the current regulations do not allow the use of electronic drugs registers even though one practice had developed such a system that had advantages over the paper based systems. Dissatisfaction with the current regulations was also evident from the finding that many practices had amended their drug registers in order to permit recording of the total amount of drug in their possession and the drug batch numbers, although the

Table 3 Views about the need for advice on policies governing controlled drugs $(n=90)$

\begin{tabular}{lll}
\hline & N & $\%$ \\
\hline $\begin{array}{l}\text { Practice has anxieties about their policies to } \\
\text { prevent diversion }\end{array}$ & 11 & 12.2 \\
$\begin{array}{l}\text { Practice would find a support and advice } \\
\text { system useful }\end{array}$ & 53 & 58.9 \\
$\begin{array}{l}\text { Preferred source of advice and support } \\
\text { Local drug action team }\end{array}$ & 19 & \\
Primary care trust & 15 & 21.1 \\
Health authority & 5 & 16.7 \\
British National Formulary & 4 & 5.6 \\
Royal College of General Practitioners & 2 & 4.4 \\
Royal Pharmaceutical Society & 1 & 2.2 \\
Other & 6 & 1.1 \\
\hline
\end{tabular}




\section{Key messages}

- Opiates prescribed for patients may be appropriated for abuse by both doctors and patients. Regulations about the storage, handling, and recording of these drugs are intended to reduce this risk.

- This investigation of opiate drugs control systems identified several weaknesses, including confusion among general practitioners about the regulations and anxiety about the procedures they were following.

- The effectiveness of systems designed to reduce risk, such as controlled drug regulations, can decline unless they are maintained through regular inspection, advice, or support.

regulations do not stipulate that this information should be recorded.

Most practices would welcome the reintroduction of some form of inspection and they would also appreciate a source of advice. Although the statutory regulations have been in force since 1985, ${ }^{1}$ GPs are not clear about their content. A source of advice would help to address this problem, but consideration should be given to including education about the controlled drugs regulations during training for GPs, practice nurses, and practice managers.

Perhaps the most striking finding of the study is that the systems to prevent the diversion of controlled drugs have been so poorly maintained. In the absence of advice and inspection the application of the system in many practices has degraded, yet the prevention of diversion of controlled drugs is a matter of concern both in the UK and other countries. Diverted drugs can reach the black market ${ }^{4}$ and may be abused by doctors themselves, and diversion of legitimate prescribing has been held responsible for many incidences of drug abuse or death in the US. ${ }^{3}$ Shipman was himself convicted in 1977 of abuse of pethidine that he had obtained through fabricated prescriptions. Evidently, systems to increase patient safety should be subject to regular review to ensure they do not fall into disrepair. Alternative methods for minimising diversion are used in other countries and in the US, for example, several states have implemented multiple copy prescription programs (MCPPs) or electronic data transfer (EDT) systems. There is some evidence that these approaches can be effective in reducing diversion, although they may also impair patient care by encouraging doctors to reduce legitimate use of controlled drugs. ${ }^{8}$ Intrusive diversion prevention schemes in other countries have had this adverse effect. ${ }^{6}{ }^{10-12}$

A National Patient Safety Agency (NPSA) was established within the NHS in England and Wales in 2001. ${ }^{13}{ }^{14}$ However, some aspects of health care are not directly supervised by the health service and the regulations governing controlled drugs are one example. These regulations include elements that relate to the work of the police and pharmacists and therefore fall within the remit of a different government department (the Home Office). The NPSA will need to collaborate with agencies external to the NHS in order to address these issues. Nevertheless, there is a clear need for a review of the regulations and of systems to assist general practices implement them consistently and effectively. The findings in this study may also be regarded as an example of the decay that occurs as a result of failure to maintain systems intended to protect patients.

\section{ACKNOWLEDGEMENTS}

This study was commissioned by Leicester, Leicestershire and Rutland Drug Action Teams and was approved by Leicestershire local research ethics committee. We thank all the general practitioners who took part.

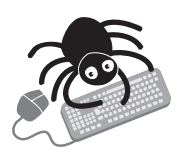

The questionnaire can be viewed on the QSHC website at www.qshc.com/supplemental.

\section{Authors' affiliations}

R Baker, P Moss, Clinical Governance Research \& Development Unit, Department of Health Sciences, University of Leicester, Leicester, UK D Upton, J Pankhania, Centre for Pharmacy Practice Research, De Montfort University, Leicester, UK.

Conflicts of interest: none.

\section{REFERENCES}

1 Department of Health, Welsh Office, Scottish Home and Health Department. Guide to the Misuse of Drugs Act 1971 and the Misuse of Drugs Regulations. London: Department of Health, 1989.

2 Anonymous. Drugs for the doctor's bag revisited. Drug Ther Bull 2000;38:65-8

3 Forgione DA, Neuenschwander P, Vermeer TE. Diversion of prescription drugs to the black market: what the states are doing to curb the tide. J Health Care Finance $2001 ; 27: 65-78$.

4 Fountain J, Strang J, Gossop M, et al. Diversion of prescribed drugs by drug users in treatment: analysis of the UK market and new data from London. Addiction 2000;95:393-406.

5 Johnson DE, Ryan KM, Gilson AM, et al. Trends in medical use and abuse of opioid analgesics. JAMA 2000;283:1710-4.

6 Rajagopal MR, Joranson DE, Gilson AM. Medical use, misuse, and diversion of opioids in India. Lancet 2001;358:139-43.

7 Baker R. Harold Shipman's Clinical Practice 1974-1998. London: The Stationery Office, 2001 ( available at www.gov.uk/hshipmanpractice).

8 Mohr JJ, Batalden PB. Improving safety on the front lines: the role of clinical microsystems. Qual Saf Health Care 2002;11:45-50.

9 Institute of Medicine. Why do errors happen? In: To err is human. Building a safer health system. Washington, DC: National Academy Press, 2000:49-68.

10 Sajan A, Corneil T, Grzybowski S. The street value of prescription drugs. Can Med Assoc J 1998; 159:139-42.

11 Simoni-Wastila L, Tompkins C. Balancing diversion control and medical necessity: the case of prescription drugs with abuse potential. Substance Use Misuse 2001;361275-96.

12 Joranson DE, Gilson AM. Pharmacists' knowledge of and attitudes towards opioid pain medications in relation to federal and state policies. J Am Pharm Assoc 2001;41:213-20.

13 Department of Health. Building a safer NHS for patients. London: Department of Health, 2001 (available at www.npsa.org.uk).

14 Department of Health. An organisation with a memory. Report of an expert group on learning from adverse events in the NHS, chaired by the Chief Medical Officer. London: Department of Health, 2000. 